\title{
El filósofo como recolector de desechos*
}

The philosopher as a waste collector

0 filósofo como coletor de resíduos

Fecha de entrega: 10 de febrero de 2012

Fecha de evaluación: 27 de abril de 2012

Fecha de aprobación: 13 de junio de 2012

Alberto Verón Ospina**

\section{Resumen}

En el presente texto planteo que la llamada "ausencia de utopías" de nuestro tiempo es una afirmación que necesita ser repensada. La historia de las ideas es el lugar donde esa afirmación se produce, y la historia misma es un campo de batallas entre escrituras que aspiran a detentar el patrimonio de concepciones del mundo, como aquellas del progreso o las utopías políticas. Frente a la concepción del progreso, los trabajos de Benjamin y Bauman han propuesto figuras como la del trapero o las vidas desperdiciadas como sugerentes cuestionamientos a la dura costra de la universalidad y del conformismo. Esas figuras presentan la posibilidad de abrirnos a nuevas utopías.

Palabras clave: utopía, memoria, historia, progreso, trapero.

* Este artículo hace parte de la investigación que el autor realiza en la Universidad Nacional de Educación a Distancia en torno al tema de la memoria en la obra de Benjamin, dentro de los procesos desarrollados para la obtención de su título de doctor en Filosofía.

* Profesor titular de la Universidad Tecnológica de Pereira, Facultad de Educación. Pertenece al grupo de investigación Filosofia y Memoria. En el 2011 publicó el libro Victimas y memorias: relato testimonial en Colombia. Correo electrónico: alveos@gmail.com 


\section{Abstract}

In this text I propose that the so-called "absence of utopias" of our times is a statement that needs to be rethought. The history of the ideas is the place where that statement is produced, and history itself is a battlefield between writings that aspire to hold the heritage of conceptions of the world, like those on progress or political utopias. As for the conception of progress, the works of Benjamin and Bauman have proposed figures such as the ragpicker or wasted lives as suggestive questionings to the hard layer of universality and conformism.

Keywords: utopia, memory, history, progress, ragpicker.

\section{Resumo}

No presente artigo eu exponho que a chamada "ausência de utopias" de nosso tempo é uma declaração que precisa ser repensada. A história das idéias é o lugar onde esta declaração ocorre, e a história mesma é um campo de batalhas entre escrituras que aspiram a possuir o património de concepções do mundo, como aquelas do progresso ou as utopias políticas. Frente à concepção de progresso, os trabalhos de Benjamin e Bauman têm proposto figuras como a do trapeiro ou as vidas desperdiçadas como sugestivos questionamentos à dura crosta da universalidade e do conformismo. Estas figuras apresentam a possibilidade de abrir-nos a novas utopias.

Palavras-chave: utopia, memória, história, progresso, trapeiro. 
Todos aquellos que se hicieron de la victoria hasta nuestros días marchan en el cortejo triunfal de los dominadores de hoy, que avanza por encima de aquellos que hoy yacen en el suelo. Y como ha sido siempre la costumbre, el botín de la guerra es conducido también en el cortejo triunfal.

Benjamin

\section{Introducción}

Del llamado "socialismo real" sabemos su final político en la Europa oriental, mientras lo que sobrevive en otras regiones del mundo como América del Sur suscita la incomprensión, la burla o el desprecio de quienes a pesar de todas las evidencias continúan pensando que no vale la pena arriesgar sus pequeñas comodidades. Pero seguimos experimentando la falta de utopías. En este aspecto, la historia es una gran partera de utopías que se han inspirado en circunstancias y en subjetividades marcadas por el impacto de la injusticia, desde los textos escatológicos de Fiore o los alzamientos campesinos de Münster, hasta el levantamiento de los pueblos indígenas de América. Lo que para el político es asunto de revolución, en el filósofo puede ser la posibilidad de que su pensamiento no sucumba a la prédica egoísta. Por eso, pensar la historia a partir de los efectos que sobre los sujetos concretos tiene el devenir, concita a que aparezcan las voces de pensadores que descreen de ciertas lógicas de dominación inscritas desde la noción misma de progreso. Son ellos quienes ponen la piedra en el zapato de las filosofías de la historia y nos abren a la utopía.

\section{Formas de narrar la historia}

Para algunos historiadores, la historia es una gran gesta, una serie de hazañas protagonizadas por héroes que exhiben su capacidad en la guerra, su astucia y liderazgo. Para otros, la historia es el encuentro entre hombres y dioses, entre naturaleza mortal y fuerzas inmortales. De ahí resulta la historia mítica, que tendrá altos momentos en las tradiciones politeístas antiguas y en la historia sagrada. "El culto, que renovaba la creación, pretendía asegurar al mismo tiempo la conservación y un desarrollo propicio de lo creado, aplacando las voluntades de los dioses" (Vallina, 2005, p. 34). 
También ha sido entendida la ciencia de Clío como un recetario, una especie de libro donde se encuentran las fórmulas y ejemplos en el pasado que pueden guiar a los gobernantes en lo que tiene que ver con el destino de la sociedad. Otros historiadores han concebido la historia como un tratado, una especie de complejo sistema de pensamiento en el que son las ideas y las teorías las que movilizan a los hombres hacia la edificación del gran artefacto de la cultura. Se trata de una historia idealista, porque pretende someter los hechos a una lógica o un sentido dado por una serie de ideas rectoras y que tiene en Hegel su más afamado representante. Otros historiadores ven la historia como un manual: un proceso de divulgación de contenidos, de resúmenes de grandes momentos, de cronologías, de recortes de vidas de héroes y de hechos. Pero también existe una concepción crítica en la cual la historia aparece como una prolongada acumulación de desastres, de víctimas que el viento huracanado del progreso deja a su paso. Esta última es la concepción de la historia que tiene Benjamin (2005) cuando se refiere al "ángel de la historia": "Este huracán lo arrastra irresistiblemente hacia el futuro, al cual vuelve las espaldas, mientras el cúmulo de ruinas crece ante él hasta el cielo. Este huracán es lo que nosotros llamamos 'progreso'” (p. 23).

Lo que uno saca en claro de la historia como historia sagrada, épica, de tratado o de manual es la coincidencia de que el proceso y los costos que ese proceso ha acarreado tienen como propósito un fin mejor. Los hechos adquieren relevancia en cuanto son los antecedentes de una evolución, de una mejora moral. ¿Pero qué pasa cuando la historia se entiende como una acumulación de desastres, como un tejido de pequeños triunfadores sobre gran cantidad de derrotados, o cuando se propone la necesidad de poner un límite a la idea de progreso con una especie de posibilidad de detención?

En la obra de Benjamin aparece una poderosa triada de personajes alegóricos que permiten interpretar el devenir humano: el cronista, la reunión de objetos en el coleccionista y la ciudad en el trapero. El coleccionista otorga a los objetos de su predilección unos nuevos sentidos. A los cálculos del comprador de valores se suma la fantasía libertaria del niño que encuentra una imagen, un juguete, un libro deseado. Al historiador y al coleccionista se les agrega el trapero que colecciona desechos; es su trabajo y transita toda la ciudad en pos de ellos. Como una especie de dios de las basuras ofrece a las sobras, a los desperdicios, a lo declarado inútil, una nueva oportunidad de renacimiento. Su raída mochila personal y el costal donde reúne su trabajo son las pruebas palpables de este esfuerzo: 
Los traperos aparecieron en mayor número en las ciudades desde que los nuevos procedimientos industriales dieron a los desperdicios un cierto valor. Trabajaban para intermediarios y representaban una especie de industria casera que estaba en la calle. El trapero fascinó a su época. Las miradas de los primeros investigadores del pauperismo están pendientes de él como embrujadas por una pregunta muda: ¿cuándo se alcanza el límite de la miseria humana? (Benjamin, 1988, pp. 31-32)

Benjamin se detiene sobre la figura del historiador y lo identifica como una especie de recuperador y clasificador de aquello que la cultura expulsa. El método de las imágenes dialécticas es la manera que tiene este personaje para restituir una nueva capacidad, una inédita fuerza hermenéutica a los fragmentos que estudia. Mientras que el coleccionista reúne y clasifica, lo que el trapero ejerce es una función semejante con aquello que se considera como acabado, en el sentido de que ha cumplido su ciclo de utilidad. El historiador al que se refiere Benjamin confronta imágenes de apariencia antitéticas, generando una nueva lectura de la historia, la cual se escribirá no desde los grandes progresos, sino desde los costos que se ha tenido que pagar por estos. "Coleccionista de desechos" (der Lumpensammler) de Benjamin, así como el chiffonier de Baudelaire, son los padres originales de una perspectiva de la historia crítica de la idea de progreso.

Sobre ese triángulo de personajes: historiador, coleccionista y trapero, se levanta lo que puede ser considerado "una filosofía de los desechos", a partir de la cual el filósofo contemporáneo latinoamericano piensa desde su experiencia de lugar.

\section{La reconstitución de lo social desde lo individual}

La concepción de la historia como progreso sigue vigente en las últimas dos décadas del siglo XX, estimulada con un nuevo elemento: el fin del comunismo como política de Estado en la Europa oriental. Resultados de esta quiebra son el impacto y el éxito de una producción bibliográfica centrada en el individualismo. Por solo citar dos casos, en ambos extremos del Atlántico, tenemos autores como Fukuyama y Lipovetszky. El primero, con uno de los libros más cuestionados pero a su vez más citados: El fin de la historia y el último hombre; el segundo con trabajos donde la ética de la posmodernidad es resuelta bajo El imperio de lo efímero. De uno a otro autor, lo que se 
evidencia es un discurso filosófico dedicado a reivindicar lo que llamo "la justificación del hombre-solo". Ambos discursos se producen en un último momento de esplendor de las economías francesas y norteamericanas. El consumo, la competencia y el narcisismo que son enaltecidos como valores pasan de ser posturas individuales a transformarse en horizontes sociales. No es extraño que durante los últimos veinticinco años, la filosofía ética y la política occidental hayan visto enaltecer la desconfianza en las utopías políticas y en los proyectos colectivos sociales, mientras que, por el contrario, los filósofos y analistas sociales se hayan identificado con el reconocimiento de una economía moral centrada en el egoísmo. Este tipo de relatos filosóficos tiene una procedencia concreta en términos geográficos: Norteamérica, Canadá y Europa. Pero, ¿qué pasa con América Latina? ¿Somos partícipes de la configuración de un mismo ethos global individualista?

Entonces, la pregunta o la inquietud que se despliega es en torno a los posibles rasgos de un pensamiento que se reconozca en las particularidades o singularidades de su procedencia. El denominado "discurso occidental” se ha llamado a sí mismo "historia universal", aunque bien sepamos que tuvo su origen en espacios geográficos bien concretos: el Mediterráneo. Este pensamiento universal europeo se ha nutrido, en la Modernidad, de sus mismas transformaciones, dejando como las crisálidas los restos de su coraza en los lugares donde ha habitado. En esta primera década del siglo XXI, ese cambio de ropaje en la filosofía puede expresarse como crisis, como posibilidad de fracturar el punto de vista universal, pues lo universal terminó siendo valorado como lo muerto y abstracto.

De allí la necesidad de una filosofía que pueda darle sugerencias a la vida, pues la filosofía se ha alejado de esta. La precariedad y la incertidumbre tanto en el mundo del trabajo como en el de los afectos es una de las situaciones más agudas de nuestra época. El guerrero solitario lucha contra la experiencia de la precariedad. La precariedad de las relaciones entre las personas, la precariedad de los trabajos y de las formas de contratación, la precariedad en las experiencias hace parte de una relación con el tiempo que se necesita y que se urge de precisar.

Las ideas filosóficas, como las mercancías, tienen también sus particulares ciclos históricos. La concepción del progreso ha sido una de las más exitosas en los últimos doscientos años, pues sobre ella se han edificado las políticas de la Modernidad. Pero el filósofo, como trapero, sabe que las mismas ideas tienen sus límites y traen sus costos epistemológicos pero también humanos. En cuanto a los costos epistemológicos, 
podemos ver cómo la idea de progreso, atravesada por la concepción lineal de la historia y puesta en juego por Estados secularizados, produce un mundo como el occidental. Esa idea de progreso, aplicada en distintas esferas económicas, sociales y políticas de manera dogmática, ha tenido costos humanos, ideas y hombres desechados, marginados o desaparecidos, al convertirse en obstáculo de las nuevas concepciones.

\section{Pensar los costos en vidas desperdiciadas}

Benjamin y Bauman son dos ejemplos de pensadores que elaboran su escritura a partir de una perspectiva negativa. Para ambos, la preparación del futuro, no en la perspectiva de un futuro que se compra como si fuéramos al supermercado a adquirir a altos costos la seguridad, sino de un futuro incierto al que nos debemos acercar con respeto, es la lección que una crítica del progreso propone como lección.

La tesis VII de Benjamin sobre la historia resulta la antecesora del barco del progreso de Bauman o del homo sacer de Agamben. Allí la imagen que nos ofrece de esa marcha triunfal de los vencedores de la historia, pisoteando a los vencidos y portando en su carruaje los bienes culturales de aquellos que fueron derrotados, parece describir a manera de carnaval festivo una civilización cuyos dominadores convirtieron en capital privado los bienes elaborados de manera prolongada por la humanidad.

En el libro Vidas desperdiciadas, Bauman (2007) realiza un recorrido por el paisaje de la Modernidad a finales del siglo XX. Su muestra es una radiografía de aquello que son los costos del progreso, pues abarca el gigantesco ejército de hombres y de mujeres desempleados, de aquellos que viven de la caridad pública, en los albergues para refugiados, de los que nacieron sin la oportunidad de un enclave duradero en el mundo del trabajo:

Desde los albores de la modernidad, cada generación sucesiva ha dejado sus náufragos abandonados en el vacío social: las víctimas colaterales del progreso. Mientras que muchos se las arreglaban para subirse al acelerado vehículo y disfrutaban al fondo del viaje, muchos otros - menos taimados, diestros, inteligentes, musculosos o aventureros- se quedaban rezagados o se les obstaculizaba la entrada al abarrotado carruaje si no quedaban aplastados bajo las ruedas (Bauman, 2007, p. 28). 
La imagen del progreso como una especie de crucero donde realizan su verano los mejores de la historia, y de los náufragos como aquellos que caen de la borda o que no alcanzan la orilla para salvarse, saca a luz el asunto de la inequidad del progreso en la historia, la poca igualdad con la cual estamos dotados para enfrentar las difíciles condiciones de la vida. Bauman ha aprendido de Benjamin el valor que tienen las imágenes negativas para cristalizar un pensamiento crítico. Las "vidas desperdiciadas" son el reverso de la modernidad líquida, son las vidas más despreciadas del juego; vidas que primero una civilización sacrifica, vidas que a cualquier momento de la historia pueden ser eliminadas.

Ser superfluo significa ser supernumerario, innecesario, carente de uso —sean cuales fueren las necesidades y los usos que establecen y el patrón de utilidad e indispensabilidad - . Los otros no te necesitan; pueden arreglárselas igual de bien, si no mejor, sin ti (Bauman, 2007, p. 24)

La versión de la historia universal como historia del progreso de Hegel a Fukuyama tiene su cara oscura en los vencidos de Benjamin y en las vidas desperdiciadas de Bauman. El espectro real de estas historias alcanza las raíces de la Modernidad a partir del hallazgo del Nuevo Mundo:

\begin{abstract}
Unos 30 a 50 millones de nativos de las tierras "premodernas", alrededor del $80 \%$ de su población total, fueron exterminados en el periodo que abarca desde la primera llegada y asentamiento de soldados y comerciantes europeos hasta comienzos del siglo XX (Bauman, 2007, p. 55).
\end{abstract}

Para aquellos que caen fuera del sistema funcional, así sea en la India, en Brasil o en África, o incluso en la actualidad en muchos distritos de Nueva York, de París o la pequeña Pereira, todos los seres humanos desposeídos de recursos devienen pronto vidas trituradas. Las puertas se han cerrado para aquel que ha caído en el desempleo, en la indigencia, en el vicio. De ellos ya no se oirá su voz, a no ser como ejemplo de un equívoco. ¿Cómo creerle a quien ha estado viviendo en las calles? Nos conmovemos ante la figura del musulmán de los campos de exterminio, pero ¿qué son esos hombres y esas mujeres que viven en y de la calle, a quienes en Colombia se les llama "desechables"? Están mudos, a lo sumo musitan una limosna. Con frecuencia se quedan literalmente mudos. 
De allí que un acto como el de la compra sea una manera de experimentarse vivo en tiempos de la globalización. Somos útiles en cuanto accedemos a las acciones del consumo. El no poder comprar es no sentirse protagonista de mover la rueda de la sociedad de consumo. Por eso, "los consumidores son los principales activos de la sociedad de consumo; los consumidores fallidos son sus más fastidiosos y costosos pasivos" (Bauman, 2007, p. 57)

En la actualidad son los consumidores de coches, de informática, de electrodomésticos, de inmuebles, de educación los que llevan sobre su espalda la justificación de la idea de progreso. Pero otra versión del progreso se escribe cuando este se lee a través de quienes tienen reducido o vedado su acceso a esos bienes o desde los costos y los restos que esos objetos de progreso generan. Digamos, entonces, que el progreso se escribe desde la metáfora de los desperdicios, concibiéndose así la otra cara del progreso. Así como somos nosotros los consumidores que llevamos sobre nuestra espalda la gran maquinara del progreso, es el trapero quien nos deja en claro cómo se construye "la frontera entre normalidad y patología, salud y enfermedad, lo deseable y lo repulsivo, lo aceptado y lo rechazado" (Bauman, 2007, p. 43).

Posiblemente, cuando haya un día del "basuriego" así como hay día del maestro, de la madre, del afrodescendiente, del niño, empecemos a darle un lugar en la memoria, en términos simbólicos de calendario, a lo que nos estorba, a aquello que nos huele mal y nos perturba. Ni la liquidez o la transparencia de la modernidad están libres de ese tufillo que trae comprender que los centros comerciales por donde deambula el flaneur, o la liquidez por la que se deslizan como patinadores los ciudadanos globales no existirían sin que en la madrugada fueran limpiados los desperdicios que esa brillantez también arroja. El trapero habita esos desechos, y el filósofo como trapero está llamado a elaborar una sensibilidad a partir de esos desechos.

Por eso, la filosofía puede nutrirse de manera poderosa de aquello que se margina y se olvida. Para esto, la categoría "memoria" resulta fundamental, pues uno de los supuestos de ella es que puede recuperar lo negado por una razón de tipo totalitario convencida de su propia validez. Pero, ¿cuál es el sentido de la recuperación de esos desechos por parte de la memoria? Si la lógica del dominio funciona de manera tal que niega u oculta lo que fue olvidado, la memoria puede significar una alternativa: rescata los recuerdos de quienes padecieron la experiencia de la violencia apelando a los relatos personales y permitiendo que los otros descubrieran ese tipo de prisión totalitaria que encarnan la negación y el olvido. He ahí la metodología de trabajo 
del filósofo en cuanto cronista de lo desechado: este explora y lee esa escritura de la memoria y de la historia en un escenario filosófico donde se proyectan el conceptosujeto de quien escribe la historia con sus motivos (el historiador benjaminiano), así como el sujeto que padece la historia y su "supuesto" progreso (la víctima) y el elemento que los reúne (el testimonio).

Se trata de un filósofo que irá por el camino contrario al de la tradición, pues parte de las márgenes, de lo olvidado y de lo mínimo. Su labor como especie de "trapero" es salvar los residuos semejantes a ruinas olvidadas. Para este filósofo-arqueólogo, el pasado se representa como unas fronteras que rodean el presente; a esos límites fronterizos llega aquello que la historia desechó, lo que el presente no considera importante. El filósofo de las ruinas llega a esos lugares fronterizos. A donde la mayoría dirige su mirada con desprecio, bajándola, volteando el rostro, enunciando apenas una frase despectiva, él, en oposición, considera que allí no están solo quienes lo merecen por su "debilidad" o sus "errores". Estos seres allí suspendidos representan el aceite que necesita la estructura misma del progreso para poder multiplicarse. El progreso se alimenta con víctimas del progreso.

Como hemos visto a lo largo de este artículo, la historia tiene un papel álgido en la filosofía. Ese papel se encuentra atravesado por una concepción lineal del tiempo que funciona para defender a quienes han impuesto una visión de mundo que justifica determinada idea de progreso. Hoy se necesita de una filosofía que reconozca cómo la civilización del progreso necesita de víctimas, para a partir de ese reconocimiento romper con esa cadena de injusticias repetidas. Una nueva teoría del conocimiento que se haga no del lado de la idea de progreso histórico, sino del lado de los vencidos de la historia.

Para lograr esto se necesita un pensar teórico que no riña con la vida misma, sino que sea capaz de entender que la teoría está conectada con la vida misma. Al decir "la vida misma" no deja el pensador de inquietarse por la vinculación o no que los libros, que las teorías y que el lenguaje puedan tener sobre los seres. Al enfrentarnos con el padecimiento del otro, al contemplar un muerto en la calle, o al escuchar el diagnóstico de una enfermedad o de la expulsión del trabajo o el adiós de un ser querido, ninguna teoría, por hermosa que sea, parece competir ante lo contundente de la experiencia de ese otro que nos interpela desde el verbo "sufrir". El sufrimiento es lenguaje, nominación del sufrimiento, pero resulta algo más: es experiencia de lo que llamamos "la vida misma". Por eso, la memoria del sufrimiento o memoria passionis 
resulta tan difícil de ser forzada a convertirse apenas en teoría del sufrimiento. En el momento que es forzada a ser teoría en el sentido tradicional, pierde su carácter vivo y pareciera cristalizarse en una función, en un modelo de dominio epistemológico, precisamente todo lo contrario a lo que pretende ser: una actitud reivindicativa, desde el lenguaje y desde la experiencia misma.

\section{El que recoge memoria es alguien que está a la escucha}

Empecemos por darle un rostro, una fisonomía, un escenario, unos intereses a quien se interesa por la memoria. En ese ámbito, la narración aparece como el lugar privilegiado de quien tiene que contar una historia. El lenguaje es el lugar donde se produce esa acción de contar. Una acción que no solamente persigue propósitos estéticos, sino que ofrece una lección, una enseñanza. En ese aspecto tenemos que quien cuenta experiencias está interesado en dejar algún tipo de lección y de aprendizaje a los que le escuchan. Esa narración, en el caso de la historia que reivindica el autor, trasciende los límites de la ciencia social y se hace con un propósito de apropiación del trauma y de superación de las heridas:

La historia no es solo una ciencia, sino no menos una forma de rememoración. Lo que la ciencia ha "establecido", puede modificarlo la rememoración. La rememoración puede hacer de lo inconcluso (la dicha) algo inconcluso, y de lo concluso (el dolor) algo inconcluso (Benjamin, 2005, pp. 473-474).

El narrador, tal como lo presenta Benjamin, es alguien que está alerta, alguien con la capacidad de recoger pequeñas partículas del sufrimiento del mundo, de sus lejanos, de sus cercanos. No estamos solamente ante la imaginación del novelista en su relación con el yo, sino en el afán de testimoniar una experiencia. Ese interés por el testimonio ha sido puesto en tela de juicio en el momento que el lenguaje deja de tener la capacidad objetiva de nombrar el mundo, para convertirse en subjetividad. No quiere esto decir que el testimonio sea un frío informe que describe acontecimiento. Por el contrario, un testimonio es fuente viva que está permeada por el punto de vista de quien cuenta la historia.

¿Pero somos conscientes de que en nuestros días la experiencia ha sido desvirtuada por la simulación de la experiencia? Por ejemplo, el carácter testimonial de la fotografía -algo tan importante en la primera mitad del siglo- o el papel aleccionador 
de la literatura resultan dudosos para los defensores de un positivismo a ultranza. Si los signos solo remiten a los signos, la posibilidad de la comunicación entre lenguaje y mundo se ha cerrado.

Los sujetos a los que invoca el narrador de Benjamin parecieran que se han desdibujado en el tiempo, sepultados por el olvido de la historia, por la violencia humana o actualmente por los simulacros agenciados por los desarrollos tecnológicos. De los esclavos y de los indígenas extintos en esa modernidad depredadora que implicó la conquista de América conocemos apenas uno que otro nombre. ¿La guerra al indio fue solamente un error de perspectiva histórica que llevó a las naciones conquistadoras a destruir esas civilizaciones ancestrales? Este es un juicio cómplice y benigno del historiador. Por el contrario, si hacemos una lectura maliciosa del progreso, resulta que era indispensable eliminar esas formas de vida; a lo sumo, apenas podrían sobrevivir como recuerdo exótico.

Las microhistorias, las historias locales y regionales, las historias de vida han sido maneras de rescatar, desde una perspectiva histórica comprometida, a los que de por sí son la mayoría. El reconocimiento que en las últimas décadas se le ha querido dar a esa multitud por medio de los lugares de la memoria, las placas conmemorativas, etc., son estrategias de recordación que más allá de su uso y abuso, convergen en la necesidad de superar el culto a héroes que terminan siendo también tiranos.

Lo que ha visto la humanidad durante los últimos años posteriores a la crisis económica del 2009: las manifestaciones de indignados en todo el planeta, los alzamientos revolucionarios en oriente contra prolongados regímenes autoritarios, las luchas de los estudiantes desde Chile hasta Colombia en defensa de una idea de educación pública, son formas que participan de esa historia de la conspiración a la que se refiere Benjamin. En estas formas actuales de lucha, los millones de vencidos del mundo realizan en la práctica su lucha, pero también registran y escriben su propia memoria.

\section{Conclusiones: una agenda de la memoria para la filosofía}

Dentro de esta agenda de preocupaciones, la memoria, más que ofrecer un método de pensamiento, estimula la necesidad de conectar dialécticamente el presente con el pasado. A la realidad humana del sufrimiento, cuyo corolario es la muerte, la memoria 
responde con una esperanza: la de la actualización del pasado para mostrar cómo lo acallado, lo negado, lo olvidado de este tiene sus efectos en los dramas del presente.

Los latinoamericanos nos hemos alimentado de restos: los restos de la ciencia producida en Europa, los restos de los modelos políticos producidos por los filósofos europeos, unos restos que nuestras élites consideran el manjar más excelso. Con esos restos hemos levantado el edificio de nuestro pensamiento y sin saberlo hemos terminado convertidos en traperos. Pero ha llegado la hora de darle una orientación a lo que ha sido un actuar ingenuo y acrítico. Es el interés u orientación ético-política que se le dé a ese collage de restos lo que dirá a futuro si fuimos capaces de hacer en Latinoamérica una filosofía con personalidad propia o si continuamos elaborando un pensamiento, una franquicia o una maquila de lo elaborado al otro lado del Atlántico.

Son las subjetividades marginadas por el progreso la verificación misma de que el modelo de la historia como progreso necesita de una urgente revisión. Ir hacia adelante es más un punto de vista para la acción que una verdad, aunque los defensores del progreso se aferren a la consideración de que esta es una verdad.

En el siglo XIX era el escritor, por medio de su palabra crítica, el que moralmente sostenía la defensa de esas grandes mayorías sometidas a una aparente mudez: él rescataba la memoria de los vencidos. En nuestro tiempo habrá que mirar los efectos que pueda tener un extendido uso de los dispositivos digitales. Las llamadas "masas" realizan sus particulares luchas y resistencias desde sus correos electrónicos, en las secciones del lector de los periódicos o en su Facebook. La inquietud es si ese rumor digital podrá cambiar en algo la estructura injusta de nuestro mundo.

\section{Referencias}

Bauman, Z. (2007). Vidas desperdiciadas. La modernidad y sus parias. Barcelona: Paidós.

Benjamin, W. (1988). Poesía y capitalismo. Madrid: Taurus.

Benjamin, W. (2005a). Libro de los pasajes. Madrid: Akal.

Benjamin, W. (2005b). Tesis sobre la historia y otros fragmentos. México: Contrahistorias. Reyes Mate, M. (2005). Filosofía de la historia. Madrid: Trotta. 